\title{
Implementing Base Data Set Custodianship - South Africa
}

\author{
Maroale Chauke ${ }^{\mathrm{a},{ }^{*}}$, Nicolene Fourie ${ }^{\mathrm{b}}$, Vutomi Ndlovu ${ }^{\mathrm{c}}$, Yvonne Moema ${ }^{\mathrm{d}}$ \\ ${ }^{a}$ National Spatial Information Framework, Dept of Agriculture, Land Reform and Rural Development, Pretoria, South Africa, \\ maroale.chauke@dalrrd.gov.za \\ ${ }^{b}$ CSIR: NextGen Enterprises and Institutions, Pretoria, South Africa, Data Subcommittee of the Committee for Spatial Information; \\ nfourie@csir.co.za \\ ${ }^{c}$ National Spatial Information Framework, Dept of Agriculture, Land Reform and Rural Development, Pretoria, South Africa, \\ Vutomi.ndlovu@dalrrd.gov.za \\ ${ }^{d}$ National Department of Transport, Pretoria, South Africa, moemay@dot.gov.za \\ * Corresponding author
}

Keywords: SDI, spatial data infrastructure, data governance, base data set coordinator, base data set custodianship

\begin{abstract}
:
Geospatial data is a strategic data asset that necessitates well-defined data governance and management processes to support evidence-based planning and decision-making. Geospatial data governance draws upon legislative and policy frameworks to facilitate data accessibility, quality, accuracy, and consistency. Governance structures and mechanisms within Spatial Data Infrastructure (SDI) are used for Geospatial data governance at local, national, regional and global levels. Data governance varies in terms of definition and implementation within SDIs [1]. Even though SDIs are well established in many countries, there is very little data available on the effectiveness of the governance structure underpinning these SDIs [1] [2] [3].

The South African Spatial Data Infrastructure (SASDI) founding principles promote effective management of spatial information through data custodianship. The SASDI is established through the Spatial Data Infrastructure Act, 2003 (Act 54 of 2003) to provide for the development of policy, institutional and technical frameworks for managing geospatial data [4]. The SDI Act makes provision for identifying base data sets that are considered crucial for SASDI and custodians are mandated through legislation to capture, maintain, manage, integrate, and distribute base data sets. The term base data set aligns with international definitions such as fundamental and core data set within the ambit of SDI.

Through the implementation of these frameworks, the Committee for Spatial Information (CSI), a statutory body established through the SDI Act, 2003, approved ten base dataset themes and adopted a Base Data Set Governance Framework for the effective management of spatial information in 2012. The framework outlines the respective roles of the coordinators and custodians in the creation and maintenance of base data sets [5]. Furthermore, building on the SDI Act, the Base Data Set Custodian Policy of 2015 provides for base data set coordinators to facilitate the governance and management of custodians in delivering base data sets. Once all systems and procedures were confirmed, the Data subcommittee of the CSI commenced with the appointment of Base Data Set Coordinators in 2017, directed by the
\end{abstract} criteria below.

\begin{tabular}{|c|c|}
\hline Criteria for base data set [6] & Criteria for base data custodian [7] \\
\hline $\begin{array}{l}\text { - Aim at complete coverage of the area of interest (Compulsory); } \\
\text { - A diversity of users from different sectors derive significant } \\
\text { benefit from their use (Compulsory) } \\
\text { - Have sufficient detail and accuracy for widespread use; } \\
\text { (Compulsory) } \\
\text { - A source for accurate referencing other datasets or for displaying } \\
\text { the results of the analysis; (Conditional: relevant for the kind of } \\
\text { dataset) } \\
\text { - The dataset is produced as a result of the core mandate of the } \\
\text { custodian (Conditional) } \\
\text { - Cannot be substituted easily or generally; (Compulsory) }\end{array}$ & $\begin{array}{l}\text { - Mandated responsibility [legislation, Cabinet directive, policy } \\
\text { or other] (compulsory); } \\
\text { - Sufficient capacity, resources and infrastructure to perform the } \\
\text { function of a base data set custodian (conditional); and } \\
\text { - A request by the CSI to be a base data set custodian } \\
\text { (compulsory). }\end{array}$ \\
\hline
\end{tabular}

Table 1. Table 1: The criteria for the identification of a base data set and base data set custodian.

Four years later, twelve Base Dataset Coordinators (coordinators) and forty-five Base Dataset Custodians (custodians) are appointed and have started executing their roles in creating and maintaining a base data set and submitting reports to 
the CSI every quarter. This paper outlines the procedure followed by South Africa in the implementation of base data themes, identification of base data sets, and the appointment and onboarding of coordinators and custodians.

Notwithstanding the strides made by some of the developed countries such as Australia and New Zealand, in establishing governance structures to regulate fundamental data themes, none of these case studies deliver a narrative from the perspective of a developing country [8]. With several developing countries still preparing to implement data custodianship, the lessons learned during the development and implementation of the data governance framework underpinning SASDI will be shared with countries that are yet to undertake this process.

The objective of this research is to document the implementation process of the Base Data Set Governance Framework for the base data themes and highlight the successes, challenges and opportunities associated with SASDI's top-down, hierarchal structure and central guidance governance framework. Finally, the paper will evaluate the requirement for adaptations to the SDI governance framework post-implementation.

The methodology will draw on a detailed case study of the implementation of the Base Data Set Governance Framework with a specific focus on the governance structures for the coordinator and data custodianship for the Theme: Transport and Hydrology: Wetlands. These two themes are selected based on their diversity and complexity associated with the underlying base data sets and custodians. Investigation of the SDI governance dynamics by analysing reports of the CSI Data Sub Committee and official documents provided by the base data set coordinator. The analysis will include the following aspects:

- Governance framework implementation:

- Implementation of Base Data Set Governance Framework by evaluating reports submitted to the CSI Data subcommittee;

- Availability and maturity of supporting documents informing the base data set governance;

- Governance framework alignment evaluation:

- Evaluate if the Base Data Set Governance Framework was implemented as is within the two base data themes or did it require modification.

- Evaluate if the Base Data Set Governance Framework structures are robust to accommodate modifications.

- Other considerations that could impact the Base Data Set Governance Framework:

- The role of the base data set coordinator in ensuring that base data set custodians do collaborate to create a base data set that adheres to policies, standards and specifications;

- The real challenges faced by base data set coordinator and custodians and how these challenges were conquered;

- The support provided by the Data subcommittee to the base data set coordinator and custodians.

The preliminary findings indicate that the primary actors driving the implementation of the Base Data Set Governance Framework and the SDI maturity of the two organisations assigned as coordinators were different for the two themes. These differences resulted in very different implementation methodologies of the Base Data Set Governance Framework within the two base data themes. However, notwithstanding the differences, the organisations tasked with the coordination function highlighted similar challenges such as capacity requirements of the coordinator function, the delineation of the roles and responsibilities of different actors in the Base Data Set Governance Framework and the requirement for an implementation guideline for the Base Data Set Governance Framework.

\section{References}

[1] Crompvoets, J., Vancauwenberghe, G., Ho, S., Masser, I., \& De Vries, W. T. (2018). Governance of national spatial data infrastructures in Europe. International Journal of Spatial Data Infrastructures Research, 13, 253-285.

[2] Sjoukema, J. W., Bregt, A., \& Crompvoets, J. (2017). Evolving spatial data infrastructures and the role of adaptive governance. ISPRS International Journal of Geo-Information, 6(8), 254.

[3] Sjoukema, J. W., Bregt, A. K., \& Crompvoets, J. (2020). Understanding Governance Dynamics: The Governing System of Spatial Data Infrastructures. International Journal of Spatial Data Infrastructures Research, 15, 1-35.

[4] South Africa (2003). Spatial Data Infrastructure Act, Act 54 of 2003.

[5] Coetzee, S., Du, J., Behr, F., Cooper, A. K., \& Odijk, M. (2019). Collaborative Custodianship through Collaborative Cloud Mapping: Challenges and Opportunities. July, 15-20.

[6] Fourie, N. (2012). Recommendations CSI: Data Subcommittee.

[7] CSI (16 February 2015a). Base Dataset Custodianship Policy, made in terms of the Spatial Data Infrastructure Act, 2003 (Act 54 of 2003), Government Gazette 38474

[8] ANZLIC (2014). The Australian and New Zealand Foundation Spatial Data Framework. Making common foundation spatial data ubiquitous across Australia and New Zealand. 